\title{
Storage Duration and Temperature Effects of Strychnos potatorum Stock Solutions on its Coagulation Efficiency
}

\author{
Rekha R. Warrier ${ }^{*}$ B. G. Singh, C. Balaji and P. Priyadarshini \\ Institute of Forest Genetics and Tree Breeding, POB 1061, R.S. Puram HPO., Coimbatore, India
}

Date Received: 18-08-2013 Date Accepted: 31-03-2014

\begin{abstract}
This study presents the effects of storage duration and temperature of Strychnos potatorum stock solution on its coagulation efficiency. Coagulation efficiency of the seed extracts on water samples depended on the initial turbidity of the water sample. The stock solutions could clarify only highly turbid solutions. The optimum dosage of the stock solutions was $5 \%$ and optimal time required was 50 minutes. $S$. potatorum stock solutions, which were kept at room temperature $\left(28^{0} \mathrm{C}\right)$, had a shelf life of only five days and were able to remove turbidity from high and low turbidity water samples and no coagulation activity was observed for medium turbidity. The highest turbidity removals were observed for stock solutions, which were kept for three days. For stock solutions which were stored in refrigerator, shelf life was extended upto seven days, and the turbidity removal efficiencies improved from $45.9 \%$ to $63.8 \%$ for low and $43.7 \%$ to $64.9 \%$ for high turbidity water samples, respectively.
\end{abstract}

Keywords: Strychnos potatorum, natural coagulant, storage duration, storage temperature, turbidity removal

\section{Introduction}

Groundwater is the preferred source for drinking water in rural areas of developing countries and it generally requires no or minimal treatment. In the event that no suitable aquifers are available, relatively clean waters from lakes or streams are preferred. However, only simple, practical technologies such as gravity chemical feed with solutions, hydraulic rapid mixing and flocculation, horizontal-flow sedimentation, and manually operated filters should be used for treatment of such waters (Schulz and Okun, 1984). The use of natural material of plant origin to clarify turbid surface waters is not a new idea. The use of herbal materials to reduce turbidity, or muddiness in the water and to remove the harmful biological material that can lead to illness is an age-old concept (Joshua and Vasu, 2013). Natural coagulants have been used for domestic household for centuries in traditional water treatment in rural areas. Sanskrit writings in India dating from several centuries BC make reference to seeds of the tree Strychnos potatorum as a clarifier (Bhishagratna, 1991), Peruvian texts from the $16^{\text {th }}$ and $17^{\text {th }}$ centuries detail the use by sailors of powdered, and roasted grains of Zea mays as a means of settling impurities. More recently, Chilean folklore texts from the $19^{\text {th }}$ century refer to water clarification using the sap from the 'tuna' cactus scientifically known as Opuntia fiscus indica (Sutherland et al., 1990). However, of all the plant materials that have been investigated over the years,

\footnotetext{
* Correspondence: rekha@icfre.org

Tel: +914222484167

ISSN 2235-9370 Print/ISSN 2235-9362 Online (C) University of Sri Jayewardenepura
} 
the seeds from $M$. oleifera have been shown to be one of the most effective as a primary coagulant for water treatment (David, 2004) of turbid water (Schulz and Okun, 1984).

For home water treatment, the materials have to be used in the form of powder or paste, $90 \%$ of which consists of substances other than polyelectrolytes. Even under such conditions, a few plant seeds make effective coagulants (Jahn, 1988), for example, seeds of the plant species of the family Loganiaceae (Strychnos potatorum), and Moringaceae (Moringa oleifera and Moringa stenopetala). S. potatorum is a small tree occurring abundantly in central and southern India. In laboratory and field studies, seeds of $S$. potatorum have shown promise as coagulant in the clarification of turbid water (Sen and Bulusu, 1962; Dhekane et al., 1970; Tripathi et al., 1976; Jahn, 1988; Sutherland et al., 1990, 1994; Folkard et al., 1995; Al-Khalili et al., 1997; Folkard and Sutherland, 2002).

Studies using the species have focused on quality of water treated by coagulation using the seed. In laboratory tests, direct filtration with $S$. potatorum seed as coagulant appeared effective in clarifying low turbidity water (Abu-Ghararah, 1983). Rodrigo (2011) conducted a study aimed at investigating the effectiveness of Strychnos potatorum seed powder coagulant for the removal of turbidity, water hardness causing cations $\left(\mathrm{Mg}^{2+}, \mathrm{Ca}^{2+}\right)$, heavy metal cations $\left(\mathrm{Pb}^{2+}, \mathrm{Cr}^{3+}, \mathrm{Cd}^{2+}\right)$, Fluoride and Chemical Oxygen Demand (COD) of treated water. Muthukumaran et al. (2013) used different types of coagulants like Moringa oleifera, Phaseolus vulgaris and Strychnos potatorum for clarifying water. However, storage studies on the seed material have not been attempted. Since home treatments demand the use of powder or paste, the goal of the present study was to assess suitability of efficient method for home water treatment in rural areas of developing countries using stock solutions of $S$. potatorum and its possible shelf life. Since, systematic studies on the effects of storage duration and condition on its performance have not yet been carried out, this study aimed to investigate the same.

\section{Materials and Methods}

\subsection{Preparation of stock solutions}

Strychnos potatorum seeds were collected from Mettupalaym, Coimbatore, India. The seeds were dried in a hot air oven for 24 hours at $50^{\circ} \mathrm{C}$. The seeds were crushed and ground to a medium fine powder with a domestic food blender (Tector). Any traces of fat was removed by mixing the powder in $95 \%$ ethanol $(5-10 \% \mathrm{w} / \mathrm{v})$ for 30 minutes and the solids separated by centrifugation and dried at room temperature. $5,000 \mathrm{mg}$ of defatted $S$. potatorum seeds powder was placed in beaker containing $0.1 \mathrm{~L}$ of distilled water. The mixture was blended to extract the active ingredient of Strychnos potatorum. The suspension was then filtered through a muslin cloth and the filtrate made up to $0.5 \mathrm{~L}$ to give a stock solution of $10,000 \mathrm{mg} / \mathrm{L}$. $10,000 \mathrm{mg} / \mathrm{L}$ of $S$. potatorum stock solution was used for test trials that were conducted to determine optimum dosages of $S$. potatorum on water samples of varying turbidities.

\section{Turbidity stock solution}

Stock kaolin solution was prepared as $1 \%$ (w/v) using distilled water, stirred slowly at $20 \mathrm{rpm}$ for 1 hour for uniform dispersion of kaolin particles. The suspension was then allowed to stand for 24 hours to allow for complete hydration of the kaolin. This kaolin suspension was used as the stock solution for the preparation of water samples of varying turbidities for the coagulation tests. Three types of turbidities were carried out namely;

$\begin{array}{lll}\text { i. } & \text { Low turbid: } & \text { less than 50 NTU } \\ \text { ii. } & \text { Medium turbid: } & \text { in between 50-200 NTU } \\ \text { iii. } & \text { High turbid: } & \text { more than 200 NTU }\end{array}$




\section{Storage of seeds stock solution}

In order to study the effects of storage temperature, the stock solutions were divided into two groups and stored at two different temperatures namely; room temperature $\left(28^{0} \mathrm{C}\right)$ and at $4^{0} \mathrm{C}$ (refrigerator). The effects of storage duration on Strychnos potatorum stock solution were investigated for $0,1,3$ and 5 days.

\subsection{Optimisation of dosage for Strychnos potatorum extracts}

Three sets of experiments were carried out with different levels of turbid solutions (Low, Medium and High).

i. Optimization of Strychnos potatorum dosage with varying concentration (5-25\%) at room temperature and $4^{0} \mathrm{C}$.

ii. Completely randomized experimental runs with varied time durations (0-150 minutes) and varying storage conditions (room temperature and $4^{0} \mathrm{C}$ ).

iii. Completely randomized experiments with varying storage conditions (room temperature and $\left.4^{0} \mathrm{C}\right)$ on different days $(0,1,3$ and 5$)$.

The water samples were agitated at the preselected intensity of rapid mixing to obtain samples of varying turbidities. During rapid mixing the crude extract of seeds were added into the samples simultaneously. Subsequently the mixture was left for sedimentation to take place. Following settling, samples were taken from the middle of each beaker using a pipette and placed in a cuvette for turbidity measurement. For determining the optimum dosage, varying stock concentrations were added into the beakers having different turbidity levels.

\subsection{Turbidity measurement}

Turbidity measurements were made using a Nephelometer (Systronics) and expressed in Nephelometric turbidity units (NTU) in relation to a control sample in a $1 \mathrm{ml}$ cuvette.

\subsection{Statistical Analysis}

Results, means and standard deviation (S.D.), of the experiments were carried out in all the methods. Statistical significance of the differences between mean values was assessed by ANOVA test.

\section{Results and Discussion}

\subsection{Optimization of dosage of Strychnos potatorum for turbidity removal}

Results on optimum dosage of $S$. potatorum to obtain highest turbidity removal on different samples are presented in Table 1. Turbidity removal efficiency of S. potatorum on low, medium and high level turbid water at 5\% was 37.5, 21.8 and 23.8\%, respectively. With increasing initial turbidity of the samples, the turbidity removal efficiency reduced. Further, for optimum dosage of S. potatorum seeds extract it was observed that increase in dosage reduced the turbidity removal efficiency. This result revealed that the low turbid water sample showed better performance in terms of turbidity removal in the case of $S$. potatorum.

\subsection{Effect of storage on optimal dosage of Strychnos potatorum for turbidity removal}

Results on the effect of storage on the optimum dosage of $S$. potatorum to obtain highest turbidity removal on different samples are presented in Table 2. Results showed that highest turbidity removal was observed with medium turbid samples. It was observed that in the case of Strychnos 
unlike in Moringa, the turbidity removal efficiency of the extracts improved with storage. Following storage of extract, the turbidity removal efficiency was improved by 26,63 and $54 \%$ for low, medium and high turbidity samples. It was observed that increase in dosage did not improve turbidity removal. However, in the low turbid samples, dosage did not show any significant reduction in efficiency. This suggests that $S$. potatorum seed extract would be effective for low turbid samples following storage of the extract under cold conditions. Turbidity removal efficiency of $S$. potatorum on low, medium and high level turbid water at 5\% was 50.7, 60 and 52.2\%, respectively. This result revealed that although the same dosage of Moringa oleifera seed extract applied on the three types of water samples, the medium turbid water sample showed better performance in terms of turbidity removal.

Table 1: Optimization of dosage of $S$. potatorum extracts on different samples.

\begin{tabular}{lccc}
\hline \multirow{2}{*}{ Strychnos potatorum Extract } & \multicolumn{3}{c}{ Turbidity Measurements (NTU) } \\
\cline { 2 - 4 } & Low & Medium & High \\
\hline Control & 54.7 & 174 & 281 \\
$5 \%$ & 34.2 & 136 & $214^{*}$ \\
$10 \%$ & 36.8 & 142 & 229 \\
$15 \%$ & 39.3 & 152 & 244 \\
$20 \%$ & 43.5 & 151 & 256 \\
$25 \%$ & 48.0 & 165 & 271 \\
Std. Deviation & 9.99 & 6.32 & 7.91 \\
Test Value t & 5.87 & 5.04 & 3.85 \\
Sig. (2-tailed) & 0.004 & 0.007 & 0.018 \\
Lower limit & 13.83 & 6.39 & 3.78 \\
Upper limit & 38.65 & 22.09 & 23.42 \\
\hline
\end{tabular}

* Significant variation $(\mathrm{p} \leq 0.05)$

Table 2: Effect of storage on optimal dosage of $S$. potatorum extracts on different samples.

\begin{tabular}{lccc}
\hline \multirow{2}{*}{ Strychnos potatorum Extract } & \multicolumn{3}{c}{ Turbidity } \\
\cline { 2 - 4 } & Low & Medium & High \\
\hline Control & 56 & 185 & 312 \\
$5 \%$ & 27.6 & 74 & $149 *$ \\
$10 \%$ & 29.2 & 80 & 257 \\
$15 \%$ & 28.2 & 86 & 293 \\
$20 \%$ & 31.6 & 98 & 294 \\
$25 \%$ & 33.2 & 113 & 295 \\
Std. Deviation & 2.80 & 8.41 & 20.09 \\
Test Value t & 38.54 & 13.62 & 1.94 \\
Sig. (2-tailed) & 0 & 0 & 0.12 \\
Lower limit & 44.80 & 40.80 & 37.51 \\
Upper limit & 51.76 & 61.68 & 42.39 \\
\hline
\end{tabular}

* Significant variation $(\mathrm{p} \leq 0.05)$

\subsection{Effect of time duration on performance of Strychnos potatorum extracts}

The effect of time period to obtain highest turbidity removal on different samples using $S$. potatorum is presented in Tables 3 and 4 and Figure 1. The extended duration was up to 150 minutes. Results showed that higher turbidity removal was observed as initial turbidity of water samples was 
increased. Though initially there was no significant variation in turbidity removal in the low and high turbid samples, following the extended duration, the variations observed was significant suggesting that increase in time period could improve turbidity removal. Medium turbid samples could be effectively coagulated in 50 minutes indicating that $S$. potatorum seed extract would be effective for medium turbid samples in shorter periods of time. With extended durations, turbidity removal efficiency increased for low and high turbid samples. However, it was observed that for medium and high turbid samples, with increasing time period, the residual turbidity was found to increase suggesting that longer durations may not be able to effectively bring in turbidity removal. The time period for significant turbidity removal efficiency of $S$. potatorum extracts on low, medium and high level turbid water was 90, 50 and 90 minutes, respectively. In this experiment, medium turbid water sample showed quicker turbidity removal.

Table 3: Effect of varying settling time on performance of $S$. potatorum extracts.

\begin{tabular}{cccc}
\hline \multirow{2}{*}{ Time in minutes } & \multicolumn{3}{c}{ Turbidity Measurements (NTU) } \\
\cline { 2 - 4 } & Low & Medium & High \\
\hline 0 & 48.4 & 182 & 252 \\
10 & 48.1 & 115 & 209 \\
20 & 44.4 & 102 & 234 \\
30 & 46.7 & 85 & 193 \\
40 & 47.8 & 86 & 193 \\
50 & 44.8 & $82^{*}$ & 192 \\
60 & 45.1 & $73^{*}$ & 184 \\
\hline
\end{tabular}

* Significant variation $(\mathrm{p} \leq 0.05)$

Table 4: Effect of extended durations of settling on performance of $S$. potatorum extracts.

\begin{tabular}{cccc}
\hline \multirow{2}{*}{ Time in minutes } & \multicolumn{3}{c}{ Turbidity Measurements (NTU) } \\
\cline { 2 - 4 } & Low & Medium & High \\
\hline 0 & 59.9 & 182 & 238 \\
90 & $40.7^{*}$ & 145 & $168^{*}$ \\
120 & $40.6^{*}$ & 140 & $162^{*}$ \\
150 & $39.6^{*}$ & 149 & 191 \\
Std. Deviation & 14.30 & 16.34 & 7.36 \\
Test Value t & 2.94 & 7.41 & 9.18 \\
Sig. (2-tailed) & 0.02 & 0.00 & 0.00 \\
Lower limit & 3.01 & 27.79 & 16.87 \\
Upper limit & 24.99 & 52.90 & 28.19 \\
\hline
\end{tabular}

* Significant variation $(\mathrm{p} \leq 0.05)$

\subsection{Effect of storage on time duration to assess performance of Strychnos potatorum extracts}

The effect of storage on the time required to obtain highest turbidity removal using Strychnos potatorum on different samples are presented in Tables 5 and 6 and Figure 2. Highest turbidity removal was observed with low turbid samples. It was observed that the time duration for turbidity removal reduced with storage. The medium turbid samples showed the fastest removal. This further reiterates the results in Table 2 that Strychnos potatorum seed extract would be effective for turbid samples following storage of the extract under cold conditions. 


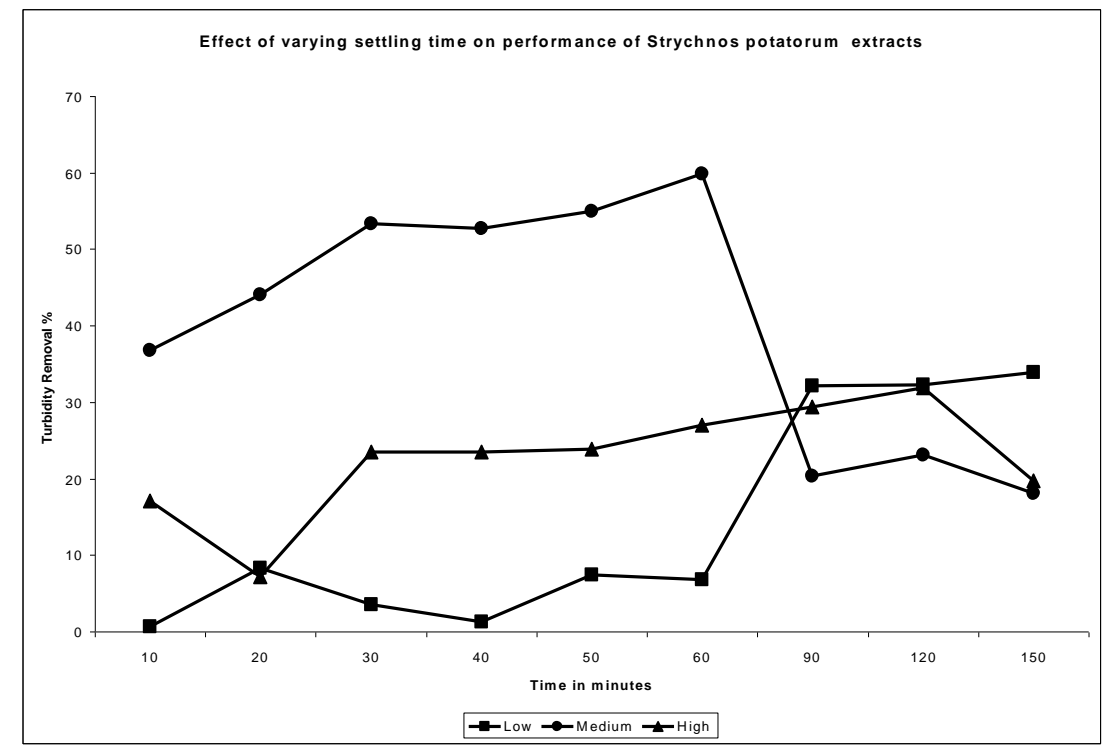

Figure. 1: Effect of varying settling time on performance of Strychnos potatorum extracts.

The low turbid samples could be coagulated in 60 minutes, the medium in 50 minutes and the high at 90 minutes. The results obtained following storage, low turbid samples could be clarified faster while the medium and high turbid samples were on par with the performance of extracts stored at room temperature. However, it was observed that for all the samples, with increasing time period, the residual turbidity was found to increase, suggesting that longer durations may not be able to effectively bring in turbidity removal. In this experiment also, medium turbid water sample showed quicker turbidity removal.

Table 5: Effect of storage on turbidity removal of $S$. potatorum extracts on different samples at varying time durations.

\begin{tabular}{cccc}
\hline \multirow{2}{*}{ Time in minutes } & \multicolumn{3}{c}{ Turbidity Measurements (NTU) } \\
\cline { 2 - 4 } & Low & Medium & High \\
\hline 0 & 62.1 & 191 & 246 \\
10 & 47.1 & 105 & 219 \\
20 & 42.2 & 86 & 202 \\
30 & 42.2 & 84 & 195 \\
40 & 41.9 & 84 & 190 \\
50 & 39.4 & $79^{*}$ & 179 \\
60 & $38.2^{*}$ & $79^{*}$ & 174 \\
\hline
\end{tabular}

* Significant variation $(\mathrm{p} \leq 0.05)$ 
Table 6: Effect of storage on turbidity removal of $S$. potatorum extracts on different samples at extended time durations.

\begin{tabular}{cccc}
\hline \multirow{2}{*}{ Time in minutes } & \multicolumn{3}{c}{ Turbidity } \\
& Low & Medium & High \\
\hline 0 & 59.9 & 182 & 238 \\
90 & $36.2^{*}$ & 139 & $147^{*}$ \\
120 & 39 & 133 & 165 \\
150 & $35.8^{*}$ & 131 & $151^{*}$ \\
Std. Deviation & 5.04 & 14.94 & 8.84 \\
Test Value t & 20.54 & 9.10 & 8.84 \\
Sig. (2-tailed) & 0.00 & 0.00 & 0.00 \\
Lower limit & 30.61 & 33.82 & 19.25 \\
Upper limit & 38.35 & 56.78 & 32.84 \\
\hline
\end{tabular}

* Significant variation $(\mathrm{p} \leq 0.05)$

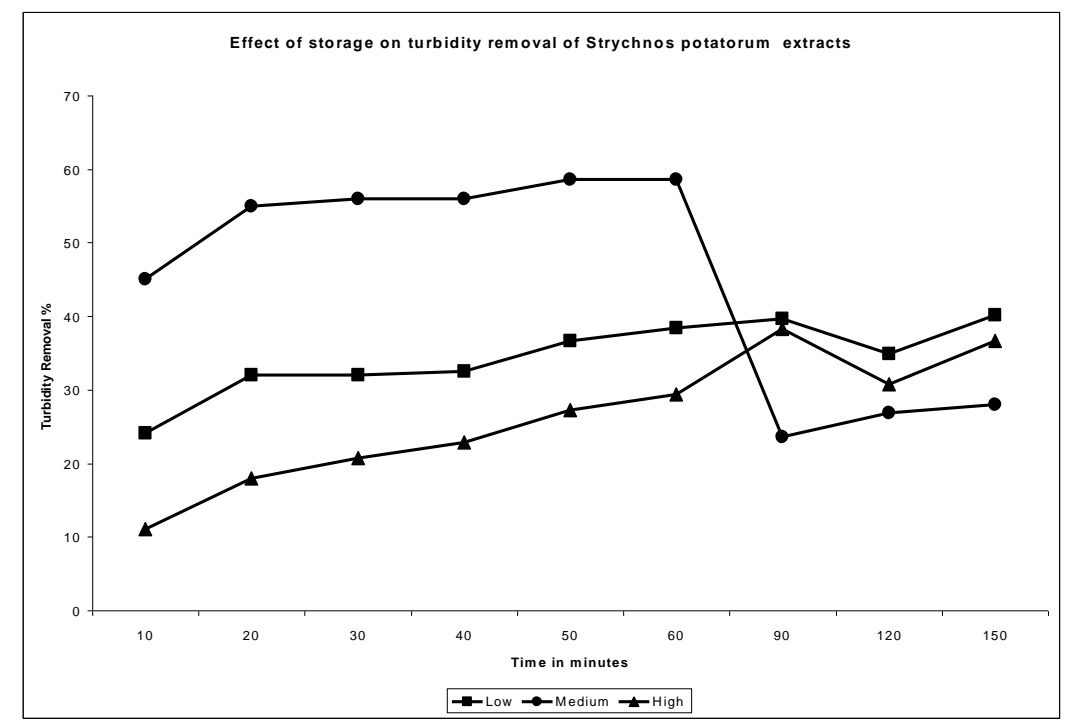

Figure. 2: Effect of storage on turbidity removal of $S$. potatorum extracts.

\subsection{Effects of storage duration of Strychnos potatorum extracts kept at room temperature $\left(28^{0} \mathrm{C}\right)$}

Table 7 shows the results of turbidity removal using Strychnos potatorum stock solutions, which were kept for 1, 3 and 5 days at room temperature. The results showed that Strychnos potatorum kept under this condition were able to remove turbidity from low and high turbidity water samples. However, it was observed that in the medium turbid samples, the residual turbidity was found higher than of the initial turbidity levels. The experiment was not conducted beyond day 5 as the extract began to decay. For the low and high initial turbidity value water samples, the highest turbidity removals were observed for stock solutions which were kept for five days. The turbidity removal efficiencies improved from 31.5 to 52.4 for low and 26.1 to $29.4 \%$ for high turbidity water samples, respectively. 
Table 7: Effects of storage duration of S. potatorum extracts at room temperature.

\begin{tabular}{lccc}
\hline \multirow{2}{*}{ Days } & \multicolumn{3}{c}{ Turbidity Measurements (NTU) } \\
\cline { 2 - 4 } & Low & Medium & High \\
\hline Day 0 & 69.9 & 136 & 245 \\
Day 1 & 47.9 & 94 & 181 \\
Day 3 & 46.7 & 199 & 189 \\
Day 5 & 33.3 & 165 & 173 \\
Std. Deviation & 11.87 &. & 3.25 \\
Test Value t & 0.03 &. & 0.01 \\
Sig. (2-tailed) & 38.70 &. & 26.13 \\
Lower limit & 9.21 &. & 18.06 \\
Upper limit & 68.19 &. & 34.21 \\
\hline
\end{tabular}

* Significant variation $(\mathrm{p} \leq 0.05)$

3.6 Effects of storage duration of Strychnos potatorum extracts kept under refrigeration $\left(4^{0} \mathrm{C}\right)$

Table 8 shows the results of turbidity removal using Strychnos potatorum stock solutions, which were kept for 1, 3 and 5 days under refrigerated conditions. The results showed that Strychnos potatorum extract kept under this condition was able to remove turbidity from low, medium and high turbidity water samples. However, it was observed that except in the high turbid samples, the medium and low turbid samples did not show a linear increase in turbidity removal. In these cases, the residual turbidity after coagulation on the third day was found higher than the first day, which further reduced on day 5 , beyond which the experiment was not conducted.

For the low and high initial turbidity water samples, highest turbidity removals were observed for stock solutions which were kept for five days. The turbidity removal efficiencies improved from 45.9 to 63.8 for low and 43.7 to $64.9 \%$ for high turbidity water samples, respectively. Another interesting observation made through these experiments was that the turbidity removal efficiency of $S$. potatorum stock solutions increased following storage and with increase in the number of days stored. The maximum was observed in the stock stored for 5 days under refrigerated conditions (64.9\%).

Table 8: Effects of storage duration of $S$. potatorum extracts kept at $4^{0} \mathrm{C}$.

\begin{tabular}{lccc}
\hline \multirow{2}{*}{ Days } & \multicolumn{3}{c}{ Turbidity } \\
\cline { 2 - 4 } & Low & Medium & High \\
\hline Day 0 & 69.9 & 136 & 245 \\
Day 1 & 37.8 & 153 & 138 \\
Day 3 & 39.6 & 85 & 88 \\
Day 5 & 25.3 & 131 & 86 \\
Std. Deviation & 11.13 & 23.90 & 12.02 \\
Test Value t & 7.94 & 1.22 & 8.30 \\
Sig. (2-tailed) & 0.02 & 0.44 & 0.01 \\
Lower limit & 23.39 & -194.13 & 27.72 \\
Upper limit & 78.67 & 235.33 & 87.41 \\
\hline
\end{tabular}

* Significant variation $(\mathrm{p} \leq 0.05)$ 
Figure 3 gives an overall view of the effects of temperature on the turbidity removal efficiency of $S$. potatorum stock solutions.

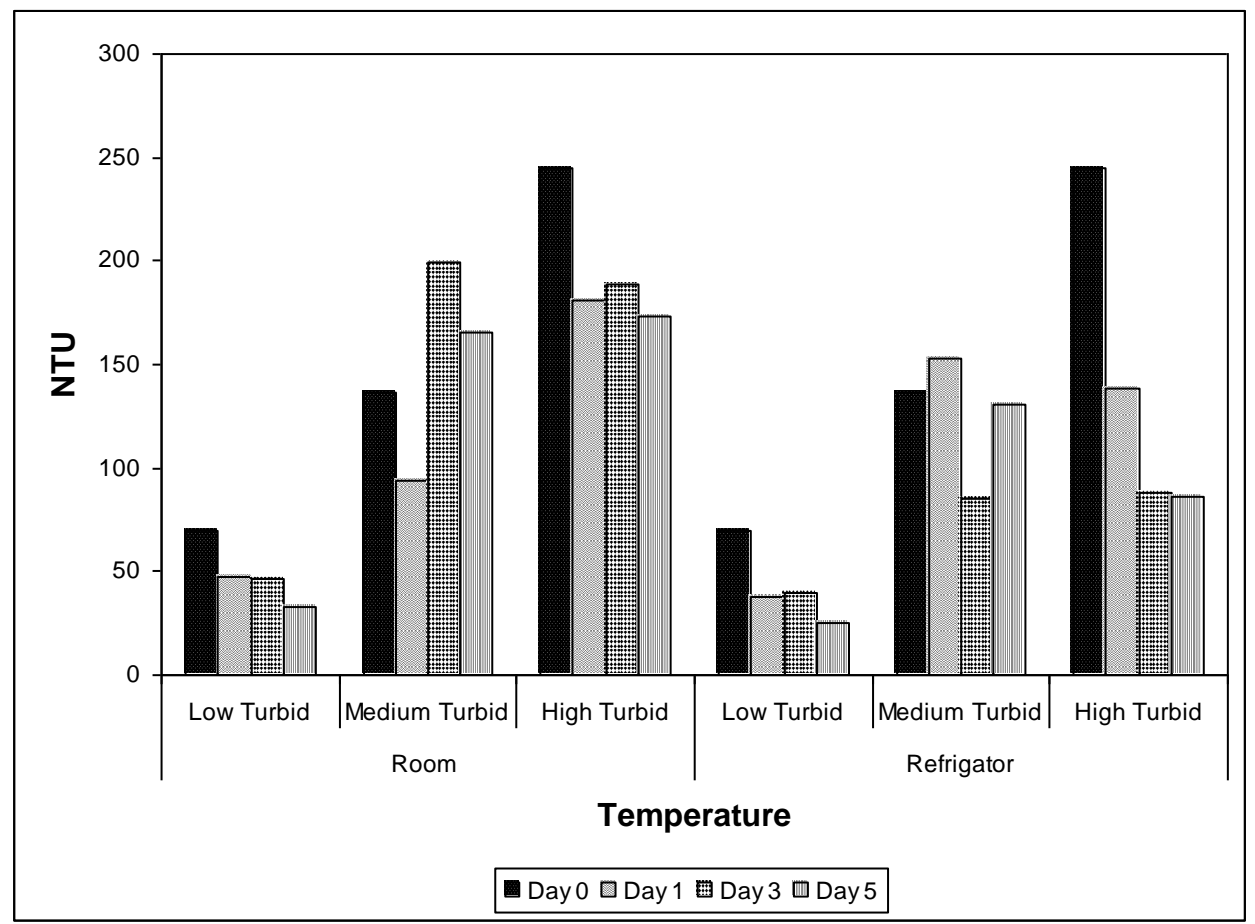

Figure 3: Effects of temperature on the storage duration of $S$. potatorum extracts.

A number of effective coagulants have been identified of plant origin. Some of the common ones include nirmali (Tripathi et al., 1976), M. oleifera (Olsen, 1987; Jahn, 1988), okra (Al-Samawi and Shokrala, 1996), Cactus latifaira and Prosopis juliflora, tannin from Valonia (Özacar and Sengil, 2000), apricot, peach kernel and beans (Jahn, 2001), and maize (Raghuwanshi et al., 2002). Bhole (1995) compared 10 natural coagulants from plant seeds. Since the early 1970's a number of studies have been carried out to determine the effectiveness of the seeds for the treatment of surface water (Olsen, 1987; Jahn 1988; Sutherland et al., 1994; Muyibi and Evison, 1995, 1996; Ndabigengesere and Narasiah, 1998; Ghebremichael et al., 2005) using different extraction methods for the active coagulant from $M$. oleifera. Utilising artificially prepared turbid water and naturally turbid raw waters, laboratory investigations have confirmed the seeds to be highly effective in the removal of suspended solids from waters containing medium to high initial turbidities (Sutherland et al., 1994). A comparative study on electro-coagulation and natural coagulation ( $M$. oleifera) methods devised for the treatment of pharmaceutical residues from both, synthetic solutions and real pharmaceutical wastewaters revealed that electro coagulation was a more effective technique than natural process (Dixit and Parmar, 2013).

Muthukumaran et al. (2013) reported that sodium chloride extract of Moringa was found to provide a high turbidity removal of $>99 \%$ compared to $\mathrm{NaOH}$ and distilled water extract of the same species. Effective turbidity by Strychnos was not effective. However, our studies have proved the efficacy of the water extract of the seeds of $S$. potatorum in clarying turbid waters to as high as $80 \%$. Rodrigo (2011) showed effectiveness of $S$. potatorum for turbidity removals of up to $92 \%, 91 \%$ and $85 \%$ for initial turbidities of 25, 50 and 100 Nephlometric Turbidity Units (NTU) respectively. Being a natural coagulant, the species is non-toxic and an effective coagulant aid useful for removing turbidity 
from water. Muthukumaran et al. (2013) report that the presence of anionic polyelectrolyte, which contains carboxylic $\left(\mathrm{COO}^{-}\right)$and hydroxyl $\left(\mathrm{OH}^{-}\right)$as main active groups which might play a role in coagulation.

\section{Conclusions}

Much progress has been made in investigating the coagulation potential of crude seed extracts as well as purified seed proteins from $M$. oleifera, which have been proven to be the main active agent in seed based coagulants. However, the species $S$. potatorum, which is popularly used in rural areas for waste water treatments, especially on a large scale has not been studies in depth. Hence the present study was taken up to investigate the performance of $S$. potatorum as a primary coagulant. Our studies showed that Strychnos extract was effective only for high turbid solutions. It was also observed that storage of extracts at $4^{0} \mathrm{C}$ did not improve its turbidity removal efficiency. Reduction in turbidity in our experiments is also comparable to those achieved by natural coagulant like $M$. drouhardii, $M$. stenopetala and $M$. peregrine seeds as reported by Jahn (1988). These results are also comparable to the result obtained by Aririatu et al. (1999), which indicates a reduction in turbidity using Moringa seeds in the range of 72.8-92.4\% while Jatropha curcas was 75.2-84.7\%. Chemical coagulants, like aluminium sulphate reduced the same turbidity of the same effluent in the range of $66.00-84.29 \%$ and ferric chloride in the range of $98.29-99.80 \%$. Turbidity removal is very dependent on proper coagulant doses and time but again the fine adjustment is less critical for highly turbid waters, which are thus also easiest to treat in this respect. The chemical composition of the coagulant in S. potatorum has been identified as a polysaccharide consisting of a 1:7 mixture of galactomannan and galactan. These findings suggest that such seed extracts may function as a particulate, colloidal and soluble polymeric coagulant as well as a coagulant aid. The presences of other constituents in these seed extracts are uncertain, because the portions of the plant also are used for medicinal purposes. Also, little has been done define, optimize and standardize conditions for their use.

Thus use of easily available indigenous plants might be seriously considered as a temporary solution where water treatment is badly needed and where the people are very motivated to start as soon as possible. Pulses, such as Lens esculenta, Cajanus indicus and Phaseolus roxborghii have been utilized with good success as coagulant aids. The above results confirmed the use of this natural coagulant as a good clarifying agent and also unveil its potential as material for water clarification through coagulation and flocculation process. These studies have indicated that clarification and prepurification (partial purification) of raw water and waste water samples can be obtained using $S$. potatorum. This method is simple, quick and does not require any special device, regulatory control and technology and would find applicability for home water treatment in rural areas of developing countries.

\section{References}

Abu-Ghararah, Z.H. 1983. Polymer application methods in direct filtration. MSc thesis. King Abdulaziz University, Jeddah, India.

Al-Khalili, R.S., Sutherland, J.P. and Folkard, G.K. 1997. Filtration with a natural coagulant. In Water and Sanitation for All: Partnerships and Innovations, Proceedings of the 23rd WEDC Conference, 1-5 September 1997. Durban, South Africa, pp.143-145.

Al-Samawi, A.A. and Shokrala, E.M. 1996. An investigation into an indigenous natural coagulant. Journal Environ. Science and Health, A31 (8):1881-1897.

Aririatu, L.E., Gwadia, O.T. and Nwaokeocha C.C., 1999. The Bioremediation Potential of some local Natural Coagulants. Nig. Journal of Microbiology, 13: 65-69. 
Bhishagratna, K.K. 1991. An English translation of Sushruta Samhita based on the original Sanskrit text. Chowkhamba Sanskrit Series Office, Varanasi, India.

Bhole, A.G. 1995. Relative evaluation of a few natural coagulants. Journal SRT-Aqua, 44(6):284-290.

David Odee. 2004. Moringa oleifera Canadian Biotechnical Division Kenya Forestry Research Institute and Moringa Medical research institute. http://www.moringa.htm.

Dhekane, N.Y., Ambawane, G.B., Patil, B.N. and Pagar, S.D. 1970. Nirmali seed as a coagulant. J. Instn Engrs India (PHE Div.), 50(10): 108-112.

Dixit, D. and Parmar, N. 2013. Treatment of pharmaceutical waste water by electro-coagulation and natural coagulation process: Review. International Journal of Technical \& Non-Technical Research, 4(5): 79-87.

Folkard, G. and Sutherland, J. 2002. Development of a naturally derived coagulant for water and wastewater treatment. Wat. Suppl. 2(5-6): 89-94.

Folkard, G., Sutherland, J. and Al-Khalili, R. 1995. Natural coagulants: A sustainable approach. In: Sustainability of water and sanitation systems, Proceedings of the 21st WEDC Conference, 4-8 September 1995, Kampala, Uganda, pp.263-265.

Ghebremichael, A.K., Gunaratna, K.R., Henriksson, H., Brumer, H. and Dalhammar, G. 2005. A simple purification and activity assay of the coagulant protein from Moringa oleifera seed. Water Res., 39:2338-2344.

Jahn, S.A.A. 2001. Drinking water from Chinese rivers: challenges of clarification. Journal of Water Supply Res. Technol., 50:15-27.

Jahn, S.A.A. 1988. Effectiveness of traditional flocculants as primary coagulants and coagulant aids for the treatment of tropical waters with more than a thousand fold flocculation in turbidity. Water Supply, 2(3-4): 8-10.

Joshua, R. and Vasu, V. 2013. Characteristics of stored rain water and its treatment technology using moringa seeds. International Journal of Life Sc. Bt \& Pharm. Res., 2(1): 155-174.

Muthuraman, G., Sasikala, S. and Prakash, N. 2013. Proteins from natural coagulant for potential application of turbidity removal in water. International Journal of Engineering and Innovative Technology, 3(1): 278-283.

Muyibi, S.A. and Evison, L.M. 1995. Optimizing physical parameters affecting coagulation of turbid water with Moringa oleifera seeds. Water Resources, 29(12): 2689-2695.

Muyibi, S.A. and Evison, L.M. 1996. Coagulation of turbid water and softening of hard water with Moringa oleifera seeds. International Journal of Environmental Studies, 56: 483-495.

Ndbigengesere, A. and Narasiah, K.S. 1998. Quality of water treated by coagulation using Moringa oleifera seeds. Water Resources, 32(3):781-791.

Olsen, A. 1987. Low technology water purification by bentonite clay and Moringa oleifera seed flocculation as performed in Sudanese village: effects on Schistosoma mansoni cercariae. Water Resources, 21(5): 517-522.

Özacar, M. and Sengil, I.A. 2000. Effectiveness of tannins obtained from valonia as a coagulant aid for dewatering of sludge. Water Resources, 34(4):1407-1412

Raghuwanshi, P.K., Mandloi, M., Sharma, A.J., Malviya, H.S. and Chaudhari, S. 2002. Improving filtrate quality using agrobased materials as coagulant aid. Water Quality Research Journal of Canada, 37(4): 745-756.

Rodrigo, P.D.T. 2011. Investigation on the natural water coagulant, Strychnos potatorum ("ingini") seed powder for drinking water treatment. A project report submitted to University of Peradeniya, Sri Lanka. pp.1-4.

Schulz, C.R. and Okun, D.A. 1984. Surface Water Treatment for Communities in Developing Countries. John Wiley \& Sons, New York. 
Sen, A.K. and Bulusu, K.R. 1962. Effectiveness of Nirmali seed as coagulant and coagulant aid. Environment Health, 4(3): 233-244.

Sutherland, J.P., Folkard, G.K. and Grant, W.D. 1990. Natural coagulants for appropriate water treatment: a novel approach. Waterlines, 8(4): 30-32.

Sutherland, J.P., Folkard, G.K., Matawali, M.A. and Grant, W.D. 1994. Moringa oleifera as a natural coagulant. In: Affordable water supply and sanitation, Proceedings of the 20th WEDC Conference, 22-26 August 1994, Colombo, Sri Lanka, pp.297-299.

Tripathi, P.N., Chaudhuri, M. and Bokil, S.D. 1976. Nirmali seed: A naturally occurring coagulant. Indian Journal of Environment Health, 18(4): 272-281. 